\title{
PENGARUH PENGEMBANGAN KARIR DAN MOTIVASI TERHADAP KINERJA KARYAWAN PADA PERUSAHAAN AIR MINUM TIRTA MANGKALUKU KOTA PALOPO
}

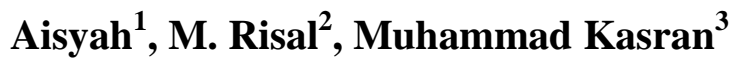 \\ Email: Aisyah@gmail.com,mrisal@stiem.ac.id, kasran@stiem.ac.id \\ ${ }^{1,2,3)}$ Prodi Manajemen Sekolah Tinggi Ilmu EKonomi Muhammadiyah Palopo
}

\begin{abstract}
Abstrak
Penelitian ini bertujuan untuk mengetahui Pengaruh Pengembangan Karir dan Motivasi terhaadap Kinerja Karyawan pada Perusahaan Air Minum Tirta Mangkaluku Kota palopo. Variabel dependen pada penelitian ini adalah Kinerja Karyawan (Y) dan variabel independen adalah Pengembangan Karir (X1) dan Motivasi (X2). Populasi dan sampel penelitian adalah 170 karyawan pada Perusahaan Air Minum Tirta Mangkaluku Kota Palopo. Data yang diperoleh dianalisis dengan menggunakan teknik analisis PLS (Partial Least Square melalui Software SmartPLS dan aplikasi SPSS 2.0. Dimana secara parsial diolah dengan teknik analisis PLS sedangkan secara simultan diolah dengan aplikasi SPSS 2.0. Berdasarkan hasil penelitian dapat disimpulkan bahwa: (1) Pengembangan Karir berpengaruh positif dan signifikan terhadap kinerja karyawan; (2) Motivasi memiliki pengaruh positif dan signifikan terhadap kinerja karyawan; (3) secara simulatan (keseluruhan) pengembangan karir dan motivasi berpengaruh positif dan signifikan terhadap kinerja karyawan.

Kata kunci : Pengembangan Karir, Motivasi, Kinerja Karyawan.
\end{abstract}

\section{PENDAHULUAN}

Sumber Daya Manusia (SDM) merupakan unsur yang sangat penting dalam suatu perusahaan. Oleh karena itu setiap perusahaan selalu berupaya untuk memiliki SDM yang berkualitas, karena tanpa SDM yang berkualitas suatu perusahaan tidak akan berjalan dengan baik. Antara SDM dan perusahaan harus memiliki hubungan yang saling membutuhkan, perusahaan membutuhkan karyawan yang berkualitas, sementara karyawan membutuhkan perusahaan untuk dapat memenuhi kebutuhan hidupnya.

Dalam perusahaan, pengembangan karir dan pemberian motivasi tentulah bukan pekerjaan yang sederhana. Apalagi jika perusahaan tersebut memiliki banyak karyawan dalam jumlah besar dan dari berbagai latar belakang budaya, usia, dan pendidikan yang berbeda.

Melihat pentingnya sumber daya manusia di dalam menunjang keberhasilan perusahaan, maka karyawan perlu dipacu kinerjanya, mengingat sumber daya manusialah yang mengatur atau mengelola sumber daya yang
lainnya.Untuk menciptakan kinerja yang tinggi, dibutuhkan adanya peningkatan kerja yang optimal dan mampu mendayagunakan potensi sumber daya manusia yang dimiliki oleh karyawan guna menciptakan tujuan organisasi sehingga akan memberikan kontribusi positif bagi perkembangan organisasi.

Berdasar uraian diatas, menjelaskan bahwa pengembangan karir dan motivasi berhubungan dengan kinerja karyawan, maka penulis tertarik untuk melakukan penelitian mengambil judul:

"Pengaruh Pengembangan karir dan Motivasi Terhadap Kinerja Karyawan pada Perusahaan Air Minum Tirta Mangkaluku Kota Palopo".

Berdasarkan uraian latar belakang masalah di atas maka pokok masalah yang dihadapi dalam penelitian ini yaitu bagaimanakah pengaruh pengembangan karir terhadap kinerja karyawan?, bagaimanakah pengaruh motivasi terhadap kinerja karyawan?, bagaimanakan pengaruh pengembangan karir dan motivasi secara bersama-sama terhadap Kinerja Karyawan?. Sesuai dengan rumusan masalah di atas, maka tujuan penelitian yaitu untuk mengetahui pengaruh pengembangan karir 
ISSN : 2339-1510

terhadap kinerja karyawan, untuk mengetahui pengaruh motivasi terhadap kinerja karyawan, untuk mengetahui pengaruh pengembangan karir dan motivasi secara bersama-sama terhadap Kinerja Karyawan.

\section{METODE PENELITIAN}

Jenis data yang digunakan yaitu data primer. Dimana peneliti menggunakan angket atau kuesioner untuk mengumpulkan informasi. Populasi dalam penelitian ini adalah seluruh karyawan Perusahaan Air Minum Tirta Mangkaluku kota Palopo. Dalam penelitian ini, sampel yang dijadikan responden adalah seluruh dari populasi dengan teknik sampling adalah sampling jenuh. Sampling jenuh adalah teknik penentuan sampel bila semua anggota populasi digunakan sebagai sampel. Pengambilan Sampel dilakukan kepada seluruh populasi yang berjumlah 170 responden dengan cara membagikan kuesioner. Metode analisis data yang digunakan yaitu Teknik analisis data yang digunakan adalah Partial Least Square (PLS) dengan langkah-langkah :

\section{Menilai Outer Model atau Measurement Model}

Terdapat tiga kriteria di dalam penggunaan teknik analisa data dengan SmartPLS untuk menilai outer model yaitu Convergent Validity, Discriminant Validity dan Composite Reliability.

\section{Convergent validity}

Convergent validity dari model pengukuran dengan refleksif indikator dinilai berdasarkan korelasi antara item score/component score yang diestimasi dengan Soflware PLS. Ukuran refleksif individual dikatakan tinggi jika berkorelasi lebih dari 0,70 dengan konstruk yang diukur.

\section{Discriminant Validity}

Discriminant validity dilakukan untuk memastikan bahwa setiap konsep dari masing variabel laten berbeda dengan variabel lainnya. Model mempunyai discriminant validity yang baik jika setiap nilai loading dari setiap indikator dari sebuah variabel laten memiliki nilai loading yang paling besar dengan nilai loading lain terhadap variabel laten lainnya.

\section{Mengevaluasi Reliability dan Average Variance Extracted (AVE)}

Kriteria validity dan reliabilitas juga dapat dilihat dari nilai reliabilitas suatu konstruk dan nilai Average Variance Extracted (AVE) dari masingmasing konstruk. Konstruk dikatakan memiliki reliabilitas yang tinggi jika nilainya 0,70 dan AVE berada diatas 0,50 .

\section{Pengujian Model Struktural (Inner Model)}

Pengujian inner model atau model struktural dilakukan untuk melihat hubungan antara konstruk, nilai signifikansi dan $R$-square dari model penelitian. Model struktural dievaluasi dengan menggunakan $R$-square untuk konstruk dependen uji t serta signifikansi dari koefisien parameter jalur struktural.

\section{Pengujian hipotesis}

Uji t (secara parsial)

Signifikansi parameter yang diestimasi memberikan informasi yang sangat berguna mengenai hubungan antara variabel-variabel penelitian. Dasar yang digunakan dalam menguji hipotesis adalah nilai yang terdapat pada output result for inner weight.

\section{Uji F (secara simultan)}

Untuk uji $\mathrm{F}$ menggunakan aplikasi SPPS, uji statistik $\mathrm{F}$ pada dasarnya menunjukkan apakah semua variabel bebas (X) yang terdiri dari pengembangan karir (X1) dan motivasi (X2) yang dimasukkan dalam model mempunyai pengaruh secara bersama-sama (simultan) dalam menjelaskan isi informasi terhadap variabel terikat terhadap kinerja karyawan $(\mathrm{Y})$

\section{PEMBAHASAN}

Karakteristik responden Berdasarkan jenis kelamin.

Berikut pada tabel 1 dibawah ini disajikan informasi mengenai data karakteristik responden berdasarkan jenis kelamin.

Tabel 1. Karakteristik Responden Berdasarkan Jenis Kelamin

\begin{tabular}{|c|c|c|c|}
\hline No & Jenis Kelamin & $\begin{array}{c}\text { Jumlah } \\
(\text { Jiwa })\end{array}$ & $\begin{array}{c}\text { Persentase } \\
(\%)\end{array}$ \\
\hline 1 & Pria & 130 & $76,5 \%$ \\
\hline 2 & wanita & 40 & $23,5 \%$ \\
\hline & Jumlah & 170 & 100 \\
\hline
\end{tabular}

Sumber data : Data Primer

Berdasarkan tabel 1 di atas tentang karakteristik responden berdasarkan jenis kelamin, dapat diketahui bahwa jumlah responden yang berjenis kelamin pria sebanyak 130 orang atau sekitar 76,5\% dari keseluruhan jumlah responden dan responden yang berjenis kelamin wanita sebanyak 40 orang atau sekitar 23,5\% dari keseluruhan jumlah responden. Hal ini mengindentifikasikan bahwa sebagian besar dari responden yang di teliti adalah laki-laki.

\section{Berdasarkan pendidikan terakhir}

Berikut pada tabel 2 dibawah ini disajikan informasi mengenai data karakteristik responden berdasarkan tingkat pendidikan. 
ISSN : 2339-1510

Tabel 2. Karakteristik Responden Berdasarkan Tingkat Pendidikan

\begin{tabular}{|c|c|c|c|}
\hline No & Pendidikan & $\begin{array}{c}\text { Jumlah } \\
(\text { Jiwa })\end{array}$ & $\begin{array}{c}\text { Persentase } \\
(\%)\end{array}$ \\
\hline 1 & SLTA & 70 & $41,2 \%$ \\
\hline 2 & D3 & 31 & $18,2 \%$ \\
\hline 3 & SARJANA & 69 & $40,6 \%$ \\
\hline & Jumlah & 170 & $100 \%$ \\
\hline
\end{tabular}

Sumber : Data Primer

Berdasarkan tabel 2 di atas tentang karakteristik responden berdasarkan pendidikan terakhir, dapat diketahui bahwa jumlah responden yang berpendidikan terakhir SLTA sebanyak 70 orang atau sekitar $41,2 \%$ dari keseluruhan jumlah responden, responden yang berpendidikan D3 sebanyak 31 orang atau sekitar 18,2 \% dari keseluruhan jumlah responden, responden yang bependidikan Sarjana sebanyak 69 orang atau sekitar 40,6 \% dari keseluruhan jumlah responden. Hal ini menunjukkan bahwa sebagian besar responden hanya mampu menyelesaikan pendidikan sampai SMA.

\section{Berdasarkan usia}

Berikut pada tabel 3 dibawah ini disajikan informasi mengenai data karakteristik responden berdasarkan usia resonden.

Tabel 3. Karateristik Responden Berdasarkan Usia

\begin{tabular}{|c|c|c|c|}
\hline No. & Usia & Jumlah & Persentase (\%) \\
\hline 1 & $20-30$ tahun & 83 & $48,8 \%$ \\
\hline 2 & $31-40$ tahun & 42 & $24,7 \%$ \\
\hline 3 & $41-50$ tahun & 41 & $24,1 \%$ \\
\hline 4 & $>50$ tahun & 4 & $2,4 \%$ \\
\hline & Jumlah & 170 & $100 \%$ \\
\hline
\end{tabular}

Sumber: Data Primer

Berdasarkan tabel 3 di atas tentang karakteristik responden berdasarkan usia, dapat diketahui bahwa jumlah responden yang berusia 20-30 tahun sebanyak 83 orang atau sekitar $48,8 \%$ dari keseluruhan jumlah responden, responden yang berusia 31-40 tahun sebanyak 42 orang atau sekitar $24,7 \%$ dari keseluruhan jumlah responden, responden yang berusia 41 50 tahun sebanyak 41 orang atau sekitar $24,1 \%$ dari keseluruhan jumlah responden, responden yang berusia > 50 tahun sebanyak 4 orang atau sekitar 2,4\% . Hal ini menunjukkan bahwa sebagian besar responden berusia 20-30 tahun.

\section{Analisis data}

Model yang telah dirancang dapat dilihat pada gambar dibawah ini :

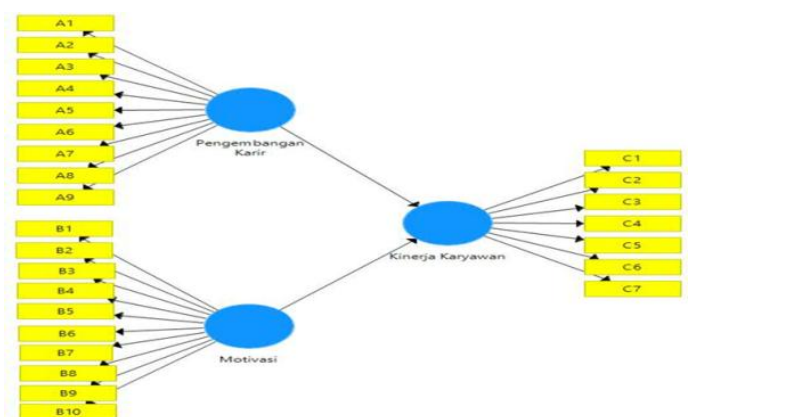

\section{Gambar 1. Model yang telah rancang}

Teknik pengolahan data dengan menggunakan metode SEM berbasis Partial Least Square (PLS) memerlukan 2 tahap untuk menilai Fit Model dari sebuah model penelitian (Ghozali, 2006). Tahaptahap tersebut adalah sebagai berikut:

\section{Menilai Outer Model atau Measurement Model}

Terdapat tiga kriteria di dalam penggunaan teknik analisa data dengan SmartPLS untuk menilai outer model yaitu Convergent Validity, Discriminant Validity dan Composite Reliability.

\section{Convergent validity}

Convergent validity dari model pengukuran dengan refleksif indikator dinilai berdasarkan korelasi antara item score/component score yang diestimasi dengan Soflware PLS. Ukuran refleksif individual dikatakan tinggi jika berkorelasi lebih dari 0,70 dengan konstruk yang diukur.

Tabel 4. Outer Loadings (Measurement Model) Model Awal

\begin{tabular}{|l|r|l|l|}
\hline & $\begin{array}{c}\text { Pengembangan } \\
\text { Karir }\end{array}$ & Morivasi & $\begin{array}{c}\text { Kinerja } \\
\text { Karyawan }\end{array}$ \\
\hline A1 & 0,354 & & \\
\hline A2 & 0,318 & & \\
\hline A3 & 0,302 & & \\
\hline A4 & 0,942 & & \\
\hline A5 & 0,955 & & \\
\hline A6 & 0,948 & & \\
\hline A7 & 0,956 & & \\
\hline A8 & 0,947 & & \\
\hline A9 & & 0,865 & \\
\hline B1 & & 0,847 & \\
\hline B10 & & 0,535 & \\
\hline B2 & & 0,835 & \\
\hline B3 & & 0,847 & \\
\hline B4 & & 0,429 & \\
\hline
\end{tabular}


ISSN : 2339-1510

\begin{tabular}{|l|l|l|l|}
\hline B5 & & 0,416 & \\
\hline B6 & & 0,451 & \\
\hline B7 & & 0,792 & \\
\hline B8 & & 0,812 & \\
\hline C1 & & 0,543 & \\
\hline C2 & & & 0,790 \\
\hline C3 & & & 0,799 \\
\hline C4 & & & 0,582 \\
\hline C5 & & & 0,632 \\
\hline C6 & & & 0,650 \\
\hline C7 & & & 0,808 \\
\hline
\end{tabular}

Sumber : Data Primer diolah

Hasil pengolahan dengan menggunakan SmartPLS dapat dilihat pada Tabel 4. Nilai outer model atau korelasi antara konstruk dengan variabel pada awalnya belum memenuhi convergen validity karena masih cukup banyak indikator yang memiliki nilai loading factor di bawah 0,70. Hal selanjutnya dilakukan adalah melakukan konstruksi ulang terhadap diagram jalur yang sebelumnya telah dibuat dengan mengeluarkan indikator yang tidak valid.

Tabel 5. Outer Loadings (Measurement Model) Model modifikasi

\begin{tabular}{|c|c|c|c|}
\hline & $\begin{array}{l}\text { Pengembangan } \\
\text { Karir }\end{array}$ & Motivasi & $\begin{array}{l}\text { Kinerja } \\
\text { Karyawan }\end{array}$ \\
\hline A4 & 0,985 & & \\
\hline A5 & 0,987 & & \\
\hline A6 & 0,987 & & \\
\hline A7 & 0,985 & & \\
\hline A8 & 0,982 & & \\
\hline B1 & & 0,959 & \\
\hline B2 & & 0,958 & \\
\hline B3 & & 0,958 & \\
\hline B7 & & 0,870 & \\
\hline B8 & & 0,885 & \\
\hline $\mathrm{C} 1$ & & & 0,931 \\
\hline $\mathrm{C} 2$ & & & 0,941 \\
\hline C6 & & & 0,914 \\
\hline C7 & & & 0,951 \\
\hline
\end{tabular}

Sumber : Data Primer diolah

Berdasarkan tabel 5 yang merupakan hasil estimasi ulang terlihat seluruh nilai loading dari masing-masing konstruk refleks menghasilkan nilai loading $>0,50$, dengan demikian model modifikasi ini telah memenuhi kriteria convergent validity yang baik.

\section{Discriminant Validity}

Discriminant validity dilakukan untuk memastikan bahwa setiap konsep dari masing variabel laten berbeda dengan variabel lainnya. Model mempunyai discriminant validity yang baik jika setiap nilai loading dari setiap indikator dari sebuah variabel laten memiliki nilai loading yang paling besar dengan nilai loading lain terhadap variabel laten lainnya. Hasil pengujian discriminant validity diperoleh sebagai berikut:

Tabel 6. Nilai Discriminant Validity (Cross Loading)

\begin{tabular}{|l|r|r|r|}
\hline & \multicolumn{1}{|l|}{$\begin{array}{l}\text { Pengembanga } \\
\text { n Karir }\end{array}$} & Motivasi & $\begin{array}{l}\text { Kinerja } \\
\text { Karyawan }\end{array}$ \\
\hline A4 & 0,985 & 0,255 & 0,421 \\
\hline A5 & 0,987 & 0,239 & 0,445 \\
\hline A6 & 0,987 & 0,289 & 0,440 \\
\hline A7 & 0,985 & 0,252 & 0,429 \\
\hline A8 & 0,982 & 0,273 & 0,446 \\
\hline B1 & 0,242 & 0,959 & 0,224 \\
\hline B2 & 0,237 & 0,958 & 0,219 \\
\hline B3 & 0,262 & 0,958 & 0,210 \\
\hline B7 & 0,238 & 0,870 & 0,188 \\
\hline B8 & 0,255 & 0,885 & 0,189 \\
\hline C1 & 0,359 & 0,265 & 0,931 \\
\hline C2 & 0,391 & 0,251 & 0,941 \\
\hline C6 & 0,448 & 0,153 & 0,914 \\
\hline C7 & 0,449 & 0,174 & 0,951 \\
\hline
\end{tabular}

Sumber : Data Primer diolah

Berdasarkan tabel 6 dapat dilihat bahwa beberapa nilai loading factor untuk setiap indikator dari masing-masing variabel laten masih memiliki nilai loading factor yang tidak paling besar dibanding nilai loading jika dihubungkan dengan variabel laten lainnya. Hal ini berarti bahwa setiap variabel laten belum memiliki discriminantvalidity yang baik dimana beberapa variabel laten masih memiliki pengukur yang berkorelasi tinggi dengan konstruk lainnya.

\section{Mengevaluasi Reliability dan Average Variance Extracted (AVE)}

Kriteria validity dan reliabilitas juga dapat dilihat dari nilai reliabilitas suatu konstruk dan nilai Average Variance Extracted (AVE) dari masingmasing konstruk. Konstruk dikatakan memiliki reliabilitas yang tinggi jika nilainya 0,70 dan AVE berada diatas 0,50. Pada tabel 7 akan disajikan nilai Composite Reliability dan AVE untuk seluruh variabel. 
ISSN : 2339-1510

Tabel 7. Composite Reliability dan Average Variance Extracted

\begin{tabular}{|l|r|r|}
\hline & $\begin{array}{l}\text { Reliabilitas } \\
\text { Komposit }\end{array}$ & \multicolumn{1}{|c|}{$\begin{array}{c}\text { Rata-rata } \\
\text { Varians } \\
\text { Diekstrak } \\
\text { (AVE) }\end{array}$} \\
\hline $\begin{array}{l}\text { Kinerja } \\
\text { Karyawan }\end{array}$ & $\mathbf{0 , 9 6 5}$ & $\mathbf{0 , 8 7 3}$ \\
\hline Motivasi & $\mathbf{0 , 9 6 8}$ & $\mathbf{0 , 8 5 9}$ \\
\hline $\begin{array}{l}\text { Pengembangan } \\
\text { Karir }\end{array}$ & $\mathbf{0 , 9 9 4}$ & $\mathbf{0 , 9 7 0}$ \\
\hline
\end{tabular}

Sumber : Data Primer diolah

Berdasarkan tabel 7 dapat disimpulkan bahwa semua konstruk memenuhi kriteria reliabel. Hal ini ditunjukkan dengan nilai composite reliability di atas 0,70 dan AVE diatas 0,50 sebagaimana kriteria yang direkomendasikan.

\section{Pengujian Model Struktural (Inner Model)}

Pengujian inner model atau model struktural dilakukan untuk melihat hubungan antara konstruk, nilai signifikansi dan $R$-square dari model penelitian. Model struktural dievaluasi dengan menggunakan $R$-square untuk konstruk dependen uji t serta signifikansi dari koefisien parameter jalur struktural.

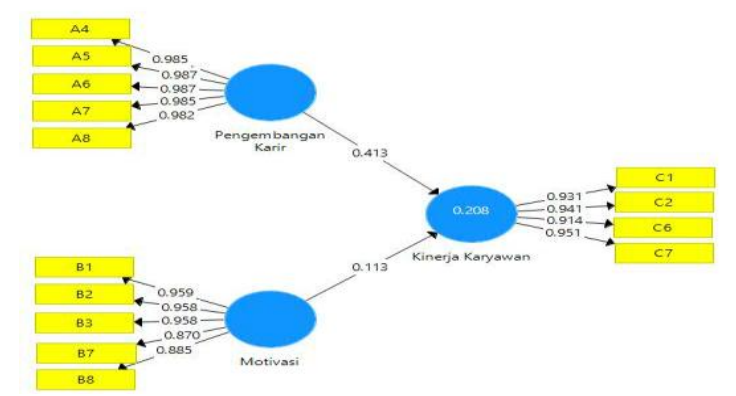

\section{Gambar 2. Model struktural yang telah diuji}

Dalam menilai model dengan PLS dimulai dengan melihat $R$-square untuk setiap variabel laten dependen. Tabel 8 merupakan hasil estimasi $R$ square dengan menggunakan SmartPLS.

Tabel 8. Nilai R-Square

\begin{tabular}{|c|c|}
\hline Var & \multicolumn{2}{|c|}{ R-square } \\
\hline Kinerja Karyawan & 0,208 \\
\hline
\end{tabular}

Sumber : Data Primer diolah

Berdasarkan tabel 8 menunjukkan nilai $R$ Square untuk variabel Kinerja Karyawan diperoleh sebesar 0,208. Hasil ini menunjukkan bahwa 20,8\% variabel Kinerja Karyawan dapat dipengaruhi oleh Variabel Pengembangan Karir dan variabel Motivasi.

\section{Pengujian Hipotesis}

\section{Uji t (secara parsial)}

Signifikansi parameter yang diestimasi memberikan informasi yang sangat berguna mengenai hubungan antara variabel-variabel penelitian. Dasar yang digunakan dalam menguji hipotesis adalah nilai yang terdapat pada output result for inner weight. Tabel 9 memberikan output estimasi untuk pengujian model struktural.

Tabel 9. Result For Inner Weights

\begin{tabular}{|l|c|c|c|c|}
\hline & $\begin{array}{c}\text { Original } \\
\text { Sample } \\
(\mathrm{O})\end{array}$ & $\begin{array}{c}\text { Sample } \\
\text { Mean } \\
(\mathrm{M})\end{array}$ & $\begin{array}{c}\text { Standard } \\
\text { Deviation } \\
\text { (STDEV) }\end{array}$ & $\begin{array}{c}\text { T Statistics } \\
(\mid \mathrm{O} / \text { STDEV| })\end{array}$ \\
\hline $\begin{array}{l}\text { Pengembangan } \\
\text { Karir -> } \\
\begin{array}{l}\text { Kinerja } \\
\text { Karyawan }\end{array}\end{array}$ & 0,413 & 0,412 & 0,079 & 5,203 \\
\hline $\begin{array}{l}\text { Motivasi -> } \\
\text { Kinerja } \\
\text { Karyawan }\end{array}$ & 0,423 & 0,404 & 0,089 & 6,269 \\
\hline
\end{tabular}

Sumber : Data Primer diolah

Dalam PLS pengujian secara statistik setiap hubungan yang dihipotesiskan dilakukan dengan menggunakan simulasi. Dalam hal ini dilakukan metode bootstrapterhadap sampel. Pengujian dengan bootstrap juga dimaksudkan untuk meminimalkan masalah ketidaknormalan data penelitian. Hasil pengujian dengan bootstrapping dari analisis PLS adalah sebagai berikut :

Pengujian Hipotesis 1 (pengaruh Pengembangan Karir terhadap Kinerja Karyawan )

Hasil pengujian hipotesis pertama menunjukkan bahwa hubungan variabel Pengembangan Karir dengan Kinerja Karyawan menunjukkan nilai koefisien jalur sebesar 0,413 dengan nilai $t$ sebesar 5,203. Nilai tersebut lebih besar dari t tabel $(1,654)$. Hasil ini berarti bahwa Pengembangan Karir memiliki hubungan yang positif dan signifikan terhadap Kinerja Karyawan yang berarti sesuai dengan hipotesis pertama dimana Pengembangan Karir meningkatkan Kinerja Karyawan. Hal ini berarti Hipotesis 1 diterima.

\section{Pengujian Hipotesis 2 (pengaruh Motivasi terhadap kinerja karyawan)}

Hasil pengujian hipotesis kedua menunjukkan bahwa hubungan variabel Motivasi dengan Kinerja Karyawan menunjukkan nilai koefisien jalur sebesar 0,113 dengan nilai t sebesar 6,269. Nilai tersebut lebih besar dari t tabel $(1,654)$. Hasil ini berarti bahwa Motivasi memiliki pengaruh yang positif da signifikan terhadap Kinerja Karyawan yang berarti sesuai dengan hipotesis kedua dimana Motivasi mampu meningkatkan Kinerja Karyawan. Hal ini berarti Hipotesis 2 diterima.

\section{Uji F (secara simultan)}

Untuk uji $F$ menggunakan aplikasi SPPS, uji statistik $\mathrm{F}$ pada dasarnya menunjukkan apakah semua variabel bebas (X) yang terdiri dari pengembangan karir (X1) dan motivasi (X2) yang dimasukkan dalam model mempunyai pengaruh 


\section{ISSN : 2339-1510}

secara bersama-sama (simultan) dalam menjelaskan isi informasi terhadap variabel terikat terhadap kinerja karyawan (Y). Hasil uji F pada penelitian ini dapat dilihat pada tabel 9 berikut ini :

Tabel 9. Uji F

ANOVA $^{\mathrm{a}}$

\begin{tabular}{|c|c|c|c|c|c|c|}
\hline \multicolumn{2}{|c|}{ Model } & $\begin{array}{l}\text { Sum of } \\
\text { Squares }\end{array}$ & Df & $\begin{array}{l}\text { Mean } \\
\text { Square }\end{array}$ & $\mathrm{F}$ & Sig \\
\hline \multirow{3}{*}{1} & Regression & 314,083 & 2 & $\begin{array}{r}157,04 \\
2\end{array}$ & $\begin{array}{r}21,57 \\
5\end{array}$ & $\begin{array}{r}, 00 \\
0^{\mathrm{b}}\end{array}$ \\
\hline & Residual & 1215,570 & 167 & 7,279 & & \\
\hline & Total & 1529,653 & 169 & & & \\
\hline
\end{tabular}

a. Dependent Variable: kinerja karyawan Y

b. Predictors: (Constant), motivasi X2, pengembangan karir X1

Sumber : Data Primer diolah

Dengan derajat kepercayaan sebesar 95\%, $F_{\text {hitung }}(21,575)>F_{\text {tabel }}(3.05)$ maka secara simultan variabel bebas $\mathrm{X}$ yang terdiri dari pengembangan karir (X1) dan motivasi (X2) mempunyai pengaruh terhadap kinerja karyawan $(\mathrm{Y})$.

\section{Pengaruh Pengembangan Karir terhadap Kinerja Karyawan}

Berdasarkan perhitungan hasil statistik bahwa konstruk Pengembangan Karir berpengaruh positif dan signifikan terhadap Kinerja Karyawan pada Perusahaan Air Minum (PAM) Tirta Mangkuluku Kota Palopo. Hal ini menunjukkan bahwa apabila Pengembangan Karir ditingkatkan maka akan mengakibatkan peningkatan kinerja karyawan pada PAM Tirta Mangkaluku Kota Palopo. Hasil penelitian tersebut di atas dibuktikan dengan pengujian secara parsial, di mana diperoleh nilai $t$ hitung untuk Pengembangan Karir adalah 5,203 $\geq \mathrm{t}$ tabel yaitu 1,654, maka dapat disimpulkan bahwa Pengembangan Karir berpengaruh terhadap Kinerja Karyawan pada PAM Tirta Mangkaluku Kota Palopo. Dengan demikian, hipotesis H1 dalam penelitian ini diterima. Hasil ini sejalan dengan hasil penelitian Ni Made Candra Megita Atma Negara (2014) yang menyatakan bahwa pengembangan karir berpengaruh terhadap kinerja karyawan PT. Pos Indonesia Kabupaten Jembrana. Hasil ini juga sejalan dengan hasil penelitian Regina Gledy Kaseger (2013) yang menyatakan bahwa Pengembangan karir berpengaruh signifikan terhadap kinerja karyawan pada PT. Matahari Department Store Manado Town Square. Hasil ini juga sejalan dengan hasil penelitian Novitri Nilam Sari (2016) yang menyatakan bahwa pengembangan karir berpengaruh terhadap kinerja karyawan pada PT. PLN (Persero) wilayah Kalimantan Utara Sektor Pembangkit Mahakam Samarinda.

Hasil ini juga sejalan dengan hasil penelitian $\mathrm{Ni}$ Luh Putu Ariesta Angga Dewi dan I Wayan Mudiarta Utama (2016) yang menyatakan bahwa pengembangan karir berpengaruh terhadap kinerja karyawan pada Karya Mas Art Gallery.

\section{Pengaruh Motivasi terhadap Kinerja Karyawan}

Berdasarkan perhitungan hasil statistik, dapat disimpulkan bahwa konstruk Motivasi berpengaruh positif dan signifikan terhadap Kinerja Karyawan pada Perusahaan Air Minum (PAM) Tirta Mangkuluku Kota Palopo. Hal ini menunjukkan bahwa apabila Motivasi ditingkatkan maka akan mengakibatkan peningkatan kinerja karyawan pada PAM Tirta Mangkaluku Kota Palopo. Hasil penelitian tersebut di atas dibuktikan dengan pengujian secara parsial, di mana diperoleh nilai t hitung untuk Motivasi adalah 6,269 $\geq \mathrm{t}$ tabel yaitu 1,654, maka dapat disimpulkan bahwa Motivasi tidak memiliki pengaruh terhadap Kinerja Karyawan pada PAM Tirta Mangkaluku Kota Palopo.

Hasil ini sejalan denga teori Wibowo, (2014;323) Motivasi adalah dorongan terhadap serangkain proses perilaku manusia pada pencapaian tujuan. Hasil ini juga sejalan dengan hasil penelitianKiki Cahaya Setiawan (2015) yang menyatakan bahwa motivasi kerja berpengaruh signifikan terhadap kinerja karyawan level pelaksana di Divisi Operasi PT. Pusri Palembang.

\section{SIMPULAN DAN SARAN Simpulan}

Dari hasil pembahasan pada penelitian di atas, dapat ditarik kesimpulan sebagai berikut :

a. Pengembangan Karir berpengaruh positif dan signifikan terhadap Kinerja Karyawan pada PAM Tirta Mangkaluku Kota Palopo.

b. Motivasi berpengaruh positif tapi tidak signifikan terhadap Kinerja Karyawan pada PAM Tirta Mangkaluku Kota Palopo.

c. Pengaruh pengembangan karir dan motivasi terhadap kinerja karyawan pada PAM Tirta Mangkaluku Kota Palopo secara simultan (keseluruhan) berpengaruh positif dan signifikan.

\section{Saran}

Berdasarkan hasil penelitian maka disarankan pada pimpinan perusahaan PAM Tirta Mangkaluku Kota Palopo, melihat tidak signifikannya variabel Motivasi terhadap kinerja karyawan maka seharusnya perusahaan lebih meningkatkan motivasi kerja karyawan dalam hal kebutuhan sosial dan kebutuhan perwujudan diri demi tercapainya kinerja karyawan yang berkualitas tinggi sehingga memberikan pengaruh yang positif kepada perusahaan. 


\section{DAFTAR PUSTAKA}

Angga, Rahayu, Syaputra. 2015. Pengaruh Kompetensi, Komitmen dan Pengembangan Karir terhadap Kinerja Karyawan PT. Bank Rakyat Indonesia (PERSERO) Kantor Wilayah Pekanbaru. Jurnal Tepak Manajemen Bisnis Vol: 7 No. 1 (Diakses tanggal17 Oktober 2017)

Audra, Bianca., Putri, B Katili., dan Shanti, K. Anggraeni. 2013. Pengaruh Motivasi, Pengembangan Karir, dan Kepuasan Kerja terhadap Kinerja Karyawan dengan Metode Structural Equation Modelling. Jurnal Teknik Industri Vol: 1 No. 4 (Diakses tanggal 17 Oktober 2017)

Badeni. 2013. Kepemimpinan dan Pelaku organisasi. Bandung: Alfabeta.

Bangun, W. 2012. Manajemen sumber daya manusia. Jakarta: Erlangga.

Endarwita dan Rini, Herlina. 2016. Pengaruh Kompensasi dan Pengembangan Karir terhadap Kinerja Karyawan. E-jurnal Apresiasi Ekonomi Vol: 4 No. 2 (Diakses tanggal 19 Oktober 2017)

Ghozali dan Hatan. 2012. Partial Least Square. Konsep, Teknik dan Aplikasi menggunakan Program Smart PLS 2.0 M3. Badan Penerbit Universitas Diponegoro:

Semarang.

2012. Aplikasi Analisis Multivariate dengan Program IBM SPSS 2.0. semarang. Badan Penerbit - Universitas Dipenogoro.

Handoko, Hani T. 2009. Manajemen Personalia dan Sumber Daya Manusia. Yogyakarta: BPFEYogyakarta.

\section{BPFE.}

, 2010. Pengantar Manajemen. Yogyakarta.

Hasibuan, M. 2008. Manajemen Sumber Daya Manusia. Bumi Aksara. Jakarta.

Kaswan. 2011. Pelatihan dan Pengembangan untuk meningkatkan Kinerja SDM. Penerbit Alfabeta. Bandung.

Kiki, Cahaya, Setiawan. 2015. Pengaruh Motivasi Kerja terhadap Kinerja Karyawan Level Pelaksana di Divisi Operasi PT. Pusri
Palembang. Jurnal Psikologi Islami Vol: 1 No. 2 (Diakses tanggal 19 Oktober 2017)

Ni Luh Putu, Ariestia, Angga, dewi dan I Wayan, Mudirtha, Utama. 2016. Pengaruh Pengembangan Karir Terhadap Kinerja Karyawan melalui Mediasi Motivasi Kerja Pada Karya Art Gallery.E-Jurnal Manajemen Unud Vol: 5 No. 9 (diakses tanggal 18 Oktober)

Ni Made, Candra, Megita, Atma, Negara. 2014. Pengaruh Pengembangan Karir terhadap Kinerja Pegawai pada PT. Pos Indonesia (Persero) Kabupaten Jembrana. Vol: 4 No. 1 (diakses tanggal 18 Oktober 2017)

Noe, R. Jhon, H. Barry, G. Patrick, W. 2011. Manajemen sumber daya manusia. Mencapai keunggulan bersaing. Cetakan kedua. Penerbit Salemba Empat. Jagakarsa, Jakarta Selatan.

Novitri, Nilam, Sari. 2016. Pengaruh Pengembangan Karir terhadap Kinerja Karyawan PT. PLN (PERSERO) Wilayah Kalimantan Utara Sektor Pembangkit Mahakam Samarinda. E-Jurnal Administrasi Bisnis Vol: 4 No. 2 Hal : 620-630 (Diakses tanggal 19 Oktober 2017)

Mondy, Wayne R and Judy Bandy Mondy. 2010. Human Resource Management Twelfth Edition, England: Pearson Education Limited.

Olivia, Theodora. 2015. Pengaruh Motivasi Kerja terhadap Kinerja Karyawan Pt. Sejahtera Motor Gemilang. AGORA Vol: 3 No. 2 (Diakses tanggal 18 Oktober 2017)

Regina, Gledy, Kaseger. 2013. Pengembangan Karir dan Self-Efficacy terhadap Kinerja Karyawan pada PT. Matahari Department Store Manado Town Square. Jurnal EMBA Vol: 1 No. 4 (diakses tanggal 18 Oktober 2017)

Santoso, singgih. 2014. Statistik Multivariat, edisi revisi, Konsep dan Aplikasi dengan SPSS. Penerbit PT. Elex Media Komputindo. Jakarta.

Simanjuntak, Payaman. 2013. Manajemen dan Evaluasi kerja. Lembaga penerbit Fakultas Ekonomi Universitas Indonesia. Jakarta. 
ISSN : 2339-1510

Slamet, Riyadi. 2011. Pengaruh Kompensasi Finansial, Gaya Kepemimpinan dan Motivasi kerja terhadap Kinerja Karyawan pada Perusahaan Manufaktur di Jawa Timur. Jurnal Manajemen dan Kewirausahaan Vol: 13 No.1 (diakses tanggal 1 januari 2018)

Sugiyono. 2010. Metode Penelitian Pendidikan Pendekatan Kuantitatif, kualitatif, dan $R \& D$. Bandung: Alfabeta.

. 2012. Metode Kuantitatif, Kualitatif, dan $R$ \&D. Bandung: CV Alfabeta.

: Alfabeta.

2013. Statistika untuk Penelitian. Bandung

Tanto, Wijaya dan Fransisca, Andreani. 2015. Pengaruh Motivasi dan Kompensasi terhadap Kinerja Karyawan pada PT. Sinar Jaya Abadi Bersama. Jurnal AGORA Vol: 3 No. 2 (Diakses tanggal 19 Oktober 2017)

Wibowo. 2014. Manajemen Kinerja, Cetakan keempat. Jakarta : PT. RAJA GRAFINDO PERSADA, Jakarta.

Widya, Parimita., Laysa, Aneu, Afrilla, Wahda., \& Agung, Wahyu, Handaru. 2015. Pengaruh Pengembangan Karir dan Motivasi terhadap Kepuasan kerja Karyawan pada PT. Pos Indonesia (PERSERO) Bekasi. Jurnal Riset Manajemen Sains Indonesia (JRMSI) Vol: 6 No. 1 (Diakses tanggal 17 Oktober 2017)

Yusuf, Palgunanto., Suparno., dan Achmad, Dwityanto. 2010. Kinerja Karyawan ditinjau dari Gaya Kepemimpinan Transformasional. Jurnal Ilmiah Berkala Psikologi Vol: 12 No. 1 (diakses tanggal 2 januari 2018). 